\title{
Market Orientation and Performance: A Study of Takaful Performance in Malaysia
}

\author{
Wan Norhayate Wan Daud ${ }^{1}$, Norizan Remli ${ }^{1} \&$ Hamizah Muhammad ${ }^{1}$ \\ ${ }^{1}$ Faculty of Business Management \& Accountancy, Universiti Sultan Zainal Abidin, Terengganu, Malaysia \\ Correspondence: Wan Norhayate Wan Daud, Faculty of Business Management \& Accountancy, Universiti Sultan \\ Zainal Abidin, Terengganu, 21300, Malaysia. Tel: 60-12-981-8045. E-mail: wnhayate@unisza.edu.my
}

Received: January 27, 2013 Accepted: February 19, 2013 Online Published: March 28, 2013

doi:10.5539/ass.v9n4p240 URL: http://dx.doi.org/10.5539/ass.v9n4p240

\begin{abstract}
This empirical study examined the effect of Market Orientation on Organizational Performance from Takaful Business's perspective in Malaysia. Apparently the framework suggests that Market Orientation has positively effects Performance of the organization. Based on the review of literatures, three hypotheses were developed to guide the study. The sampling frame was top management, middle management, junior management and executives in the Marketing department of six composite Takaful Operators headquarters in Malaysia. A total of 162 questionnaires were distributed and 111 responded in which they were analyzed. Findings from the study found that all of these hypotheses were supported the framework thus providing new ideas for the representative specially Marketing Manager from Takaful industry to increase their level of market penetration which is still low at the present. Several practical implications from the study found are also discussed.
\end{abstract}

Keyword: market orientation, performance, Takaful and Malaysia

\section{Introduction}

Organizational performance is the ultimate relevant to scholars to do the management research. Study by Richard, Devinney, Yip, and Johnson (2009) reveals a multidimensional conceptualization of organizational performance. In 1972, Alchian and Demsetz (1972) conceptually viewed performance as the comparison of the value created by a firm with the value owners expected to receive from the firm. Further, Venkatraman and Ramanujam (1986) also define financial and operational performance. At this time, Homburg, Hoyer, and Fassnacht (2002) made a fundamental distinction between nonfinancial and financial performance measures. They defined the nonfinancial company performance is the effective organization's marketing activities and can be evaluated through customer satisfaction, customer loyalty, customer benefit and market share. Meanwhile, financial performance refers to the profitability and can be measured by return on sales, return on investment and return on assets.

Based on the contribution was made to organizational performance, marketing strategies become tremendously beneficial to the organization. Market orientation's relationship is one of the marketing strategy tools towards the organizational performance was largely established by Im and Workman Jr., (2004). Market Orientation was proved connected with the business performance and was widely held to be self-evident until the mid-1980's, when marketing practitioners found that they were increasingly out-marketed by superior performance (Ellis, 2005).

The concept of market orientation adopted by practitioners over 40 years has become an important element of research. Market orientation in literature represents superior skills in understanding and satisfying customers (Day, 1990), a set of beliefs that put the customer's interest first (Deshpande, Farley, \& Webster, 1993), the ability of the organization to generate information as well as spread information and respond to customers and competitor's needs (Kohli \& Jaworski, 1990), whereas Narver and Slater, (1990), composed three behavioral components; customer orientation, competitor orientation and interfunctional coordination (Ruibyte, Haahti, \& Pesämaa, 2007).

Although market orientation creates superior performance in the western economies but in other countries such as developing countries especially, the implementation still leaves some gaps in both the theory and practice of marketing (Sany, Rushami, \& Rozita, 2009). Studies related to market orientation and it is relationship on the 
organizational performance in the service industry such as insurance and Takaful especially in Malaysia context has been scarce. Thus, the objectives of the study are to identify the relationship between Market Orientation and Performance of Takaful business in Malaysia. Therefore, this study is structured as follows: Section 2 presents a literature review, Section 3 discusses the methodology while Section 4 presents the results and discussion and finally the conclusion and implication.

\section{Literature Review}

\subsection{Underlying Theory}

Resource-Advantage Theory of Competition (R-A Theory) is chosen as the underlying theory for this study. R-A Theory suggested ten essential criteria that can observe in order to suit the way how it works. They are; (i) it looks demand is varies within industries, (ii) the consumer information is imperfect and costly to be obtained, (iii) human motivation is a constraint by self-interest that is fear of personal effect, (iv) organizations' objective is always superior financial performance, (v) organization's information is imperfect and costly to be obtained, (vi) resources of the organization are mainly financial, physical, legal, human, organizational, informational and relational, (vii) the characteristics of the resources are varies and imperfectly mobile, (viii) the role of management is to recognize, understand, create, select, implement and modify strategies to be applicable to the organization, (ix) the role of the environment in the organization is to influence the conduct and performance of the organization and $(\mathrm{x})$ the competition within the industries is the comparative advantage to the organization (Hunt \& Morgan, 1995).

Generally based on R-A Theory, the consumers' tastes and preferences always change. For that reason, Hunt and Morgan (1995) suggested that the firms which look for superior financial performance, they need to engage major innovations as a new resource to become competitive advantage as compare to the competitors. Within the R-A theory framework, market orientation serves as the intangible resources offered value for market segments to the firm to produce efficiently and/or effectively. The application of this theory will lay the organization to observe and take up market orientation as one of the important strategy in performing their marketing strategy to achieve superior performance.

\subsection{Market Orientation and Organizational Performance Relationship}

Growing from the earlier terms "marketing philosophy" and "marketing concept", Market Orientation had been proved to have a connection with the business (Ellis, 2005). Cho (2004) indicated that studies on the marketing concept and organizational performance link have empirically supported by studies of Narver and Slater (1990), Narver, Slater, and Tietje (1998), Ruekert (1992), Jaworski and Kohli (1993), Slater and Narver (1994), Pelham and Wilson (1996), Deshpande et al. (1993) and Ngai and Ellis (1998).

Using a sample of 159 hospitals, Kumar, Subramaniam, and Yauger (1998) had proved the existence of a strong relationship between market orientation and various measures of organizational performance. Even though the study focus on the hospitals which consist of profit and non-profit organization, results shows that market orientation affects every aspect of organizational performance in the industry.

In a study of market orientation and company profitability, further evidence incorporating longitudinal data, Dawes (2000) found that the components of a market orientation, competitor orientation emerged the strongest association with performance. Likewise, study by Ellis (2006) also supports the relationship between market orientation and firm performance. In general, firms can improve their performance by encouraging better customer service as compared to their rivals. Reviewing the previous studies on the relationship between market orientation and organizational performance lead to the conclusion of the positive relationship between market orientation and organizational performance is existed.

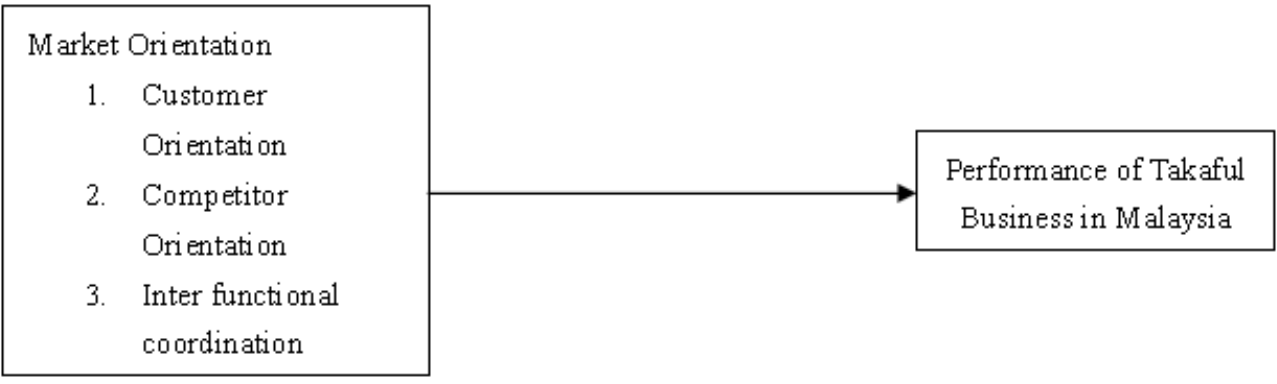

Figure 1. 
Figure 1 shows the conceptual framework for this study is built based on the Resource-Advantage Theory of Competition (R-A Theory). On the basis of previous studies explained above, the area of this study covers Market Orientation and how these influence the performance of Takaful Business in Malaysia.

\section{Methodology}

\subsection{Hypotheses}

\subsubsection{Relationship between Customer Orientation and the Performance of Takaful Business in Malaysia.}

The heart of a market orientation is its customer focus (Slater \& Narver, 1994). The customer is the foundation of a business and keeps it in existence (Drucker, 2007; p.61). Customer orientation is defined as "the sufficient understanding of one's target buyers to be able to create superior value for them continuously" (Narver \& Slater, 1990). To create superior value for buyers continuously requires a seller to understand a buyer's entire value chain, not only as it is today but also as it evolves over time (Slater \& Narver, 1994).According to Han et al., (1998) customer orientation advocates a continuous proactive nature of service towards meeting the demand of the customers. In line with this reasoning, study by Deshpande, Farley and Webster (1993) shown a positive correlation between customer orientation and innovative firms (Han et al., 1998). Based on the above literature, the study hypothesizes, that:

H1a: There is a positive relationship between Customer Orientation and the Performance of Takaful Business in Malaysia

3.1.2 Relationship between Competitor Orientation and the Performance of Takaful Business in Malaysia.

Creating superior customer value requires more than just focusing on customers (Slater \& Narver, 1994). According to Slater and Narver (1994) superior value requires that the sellers identify and understand the principal competitors' short-term strengths and weaknesses and long-term capabilities and strategies of both, current and potential competitors. Basically, competitor orientation focuses on the following questions; (1) Who are the competitors? (2) What technologies do they offer? (3) Do they represent an attractive alternative from the perspective of the target customers (Slater \& Narver, 1994)? A seller should adopt a chess-game perspective of its current and principal potential competitors and continuously examine the competitive threats from intent and value-creation capabilities. These are the steps that the organization needs to consider for developing a niche market like chess game such as 1) Know where you want to go before you start moving, 2) Predict the moves that your competition is going to make, 3) Predict the moves that your customer is going to make, 4) Make calculated moves with everything you do, 5) Know and operate your business with the big picture in mind, not just the quick sale, 6) As soon as you see an opportunity, you take it immediately and not to wait and see. This is crucial information to a seller in developing its contingency competitive strategies (Slater \& Narver, 1994). The objective of competitor-centered methods is to keep pace with or even stay ahead of the rest of the field; one would expect a competitor-oriented corporate culture to facilitate innovation. Based on the above literature, the study hypothesizes, that:

H1b: There is a positive relationship between Competitor Orientation and the Performance of Takaful Business in Malaysia.

3.1.3 Relationship between Inter-functional Coordination and the Performance of Takaful Business in Malaysia.

The third component in the series of core market orientation verified by Narver and Slater (1990) is interfunctional coordination. It refers to "the coordinated utilization of company resources in creating superior value for target customers" (Narver \& Slater, 1990). This means that any individual in any function in a seller firm can potentially contribute to value creation (Slater \& Narver, 1994). Several decades after the advent of the marketing concept, there are indications that practitioner acknowledging the responsibility of market orientation as beyond scope of the marketing department alone (Han et al., 1998). Further, Han et al., (1998) explained that as functions are integrated across departments in an organization, the problem-solving capabilities are potentially enhanced by individuals working toward the common goal; however, if personnel in different departments do not open up to each other, they are more likely conform to their routine mode of problem-solving and less likely to be creative and take risks. Openness in communication across function is very important. According to Zaltman, Duncan and Holbek (1973) in Han et al. (1998), openness in communication relates to organizational capacity to innovate. In other words, more creativity or innovativeness is brought to bear on increasing effectiveness and efficiency for customers' value. Evidence supporting how interfunctional integration and openness in communication relate to organizational innovativeness is on hand from a vast number of researches focusing on organizational characteristics and their implications (Han et al., 1998). Hence, this study hypothesizes that:

H1c: There is a positive relationship between Inter-functional Coordination and the performance of Takaful 


\section{Business in Malaysia.}

\subsection{Questionnaire Design}

Structured questionnaires were asked to respondents where it consisted of three sections. Data collected from the survey instrument (questionnaire) is divided into three sections. Section A will be measuring the organizational Performance of the Takaful operators in Malaysia. Section B will be measuring the Market Orientation components; Customer Orientation, Competitor Orientation and Inter-functional Coordination. Section C will collect data on the demographic profile of the respondents and their firms or organizations.

Section A gathered information on the organizational performance using non-profit measures. Companies' representatives were asked to circle the companies' performance on each of the seven statements. It consists of information related to their competitors, how the companies have performed with respect to (1) achieving customer satisfaction, (2) providing customer benefits, (3) attaining desired market share, (4) attaining existing customers, (5) attaining desired growth, (6) attaining new customers and (7) building a positive organizational image. The purpose of this study is to identify the performance of the Takaful business in Malaysia whether the result indicates much worse, moderate or much better following measures by Homburg et al. (2002).

Section B gathered information on the independent variable; market orientation, which in this study is the factor with attributes which will influence the organizational performance. It consists of three dimensions; customer orientation, competitor orientation an inter-functional coordination. Companies' representatives were asked six questions related to customer orientation. (1) My company understands the needs of customers, (2) My company creates values for customers, (3) My company focuses less on customers commitment, (4) My company is less concerned with customer satisfaction, (5) My company responds to customers' requests effectively and (6) My company provides follow-up services.Competitor orientation in this study is measured by examining the four elements: (1) Salesperson share competitor information, (2) Respond rapidly to competitors' action, (3) Top managers discuss competitors' strategies and (4) Target opportunities for competitive advantage. Inter-functional coordination in this study is measured by examining the five elements; (1) inter-functional customer calls, (2) information shared among functions, (3) functional integration in strategy, (4) all functions contribute to customer value and (5) share resources with other business units. All the statements on market orientation were adopted from Narver and Slater (1990). The Companies' representatives were requested to rate on a scale of 1 (Never) to 5 (Always) on each of their companies' daily operation statements.

\subsection{Research Sample}

The sampling frame of this study was top management, middle management, junior management and executives in the Marketing department of six composite Takaful Operators headquarters in Malaysia. A total of 162 questionnaires were distributed and 111 responded in which they were analyzed.

\subsection{Analysis Data}

Five main statistical techniques are to be undertaken in this study, namely descriptive analysis, factor analysis, reliability analysis, correlation analysis and regression analysis.

\section{Results and Discussion}

This study examines the relationship between market orientation and performance of Takaful business in Malaysia. Performance is measured by one dimension and market orientation is measured by three dimensions. Thus, the three sub-hypotheses constructs are;

H1a: there is a positive relationship between customer orientation and performance of Takaful business in Malaysia,

$\mathrm{H} 1 \mathrm{~b}$; there is a positive relationship between competitor orientation and performance of Takaful business in Malaysia,

H1c; there is a positive relationship between inter-functional coordination and performance of Takaful business in Malaysia.

First of all, the study employed factor analysis for performance of Takaful business in Malaysia. In this case nine (9) items in section A representing information on performance of the Takaful Business in Malaysia gathered as per table 4.1 below. 
Table 1. Factor analysis for performance of Takaful business in Malaysia

\begin{tabular}{lc}
\hline & Component \\
\hline Achieving customer satisfaction & 1 \\
Providing customer benefits & .793 \\
Attaining desired market share & .753 \\
Attaining existing customers & .719 \\
Attaining desired growth & .772 \\
Attaining new customers & .661 \\
Building positive organizational image & .781 \\
Eigenvalue & .640 \\
Percentage Variance explained & 3.767 \\
KMO & 53.81 \\
\hline
\end{tabular}

The result indicated that the KMO measure of sampling adequacy at 0.827 , indicating that the items were interrelated and they shared common factors. According to Kaiser and Rice (1974), KMO within 0.8 was Meritorious. Barlett's test of sphericity was also found to be significant (Approx. Chi-square $=320.869, \mathrm{p}<0.05$ ), indicating the significance of the correlation matrix and thus the suitability for factor analysis. The individual MSA values ranged from 0.752 to 0.873 indicating that the data matrix was suitable to be the factor analyzed. Results of the priori Promax rotated analysis indicated one significant component with eigenvalue 3.767 that explained $53.81 \%$ of the total variances.

In the same measurement of the Performance of Takaful Business in Malaysia (Dependent variable) factor analysis was undertaken to assess the validity of Market Orientation (Independent Variable). In this case, 15 items in section B represented information on the Market Orientation activities for the composite Takaful Operators in Malaysia.

Table 2. Factor analysis for market orientation

\begin{tabular}{lccc}
\hline & \multicolumn{3}{c}{ Component } \\
\hline My company understands the needs of customers & 1 & 2 & 3 \\
My co. creates values for customers & $\mathbf{. 5 5 0}$ & -.284 & .409 \\
My co. focus less on customers commitment & $\mathbf{. 5 7 5}$ & -.314 & .375 \\
My co. is less concerned with customer satisfaction & .500 &. $\mathbf{7 4 3}$ & .155 \\
My co. responds to customers' request effectively & .481 & $\mathbf{. 6 5 9}$ & .236 \\
My co. provides follow-up services & $\mathbf{. 6 0 3}$ & -.224 & .419 \\
My co. responds more rapidly to competitors' actions & $\mathbf{. 6 5 0}$ & -.282 & .373 \\
My co. targets opportunities for competitive advantage & $\mathbf{. 8 0 5}$ & .033 & .002 \\
Top managers discuss competitors strategies & $\mathbf{. 7 3 8}$ & -.044 & -.326 \\
My co. is able to predict industry or sector trends & $\mathbf{. 7 9 9}$ & -.163 & -.279 \\
People in charge in various services discuss competitor info. & $\mathbf{. 8 1 0}$ & .010 & -.413 \\
The mark. people in our co. rarely interact with other dept. & $\mathbf{. 8 2 1}$ & -.061 & -.295 \\
All the dept(s) contribute to generating customer value & .328 & $\mathbf{. 7 0 5}$ & .022 \\
Info about our market is shared with very few dept(s) & $\mathbf{. 7 4 0}$ & -.314 & .022 \\
There is culture of mutual cooperation between dept(s) & .542 & $\mathbf{. 5 5 7}$ & .069 \\
Eigenvalues & $\mathbf{. 7 5 2}$ & -.206 & -.197 \\
Percentage Variance Explained & 6.576 & 2.277 & 1.190 \\
KMO & 43.839 & 15.178 & 7.936 \\
\hline
\end{tabular}


The results showed based on Table 4.2 stated that the KMO measure of sampling adequacy at 0.858 , indicating that the items were strongly interrelated and they shared common factors. According to Kaiser and Rice (1974), KMO within 0.8 was Meritorious. Barlett's test of sphericity was also found to be significant (Approx. Chi-square=978.530, $\mathrm{p}<0.05$ ), indicating the significance of the correlation matrix and thus the suitability for factor analysis. The individual MSA values ranged from 0.714 to 0.926 indicating that the data matrix was suitable to be the factor analyzed. Results of the Promax rotated analysis indicated three significant component with eigenvalues $6.58,2.28$ and 1.19 that explained $43.839 \%, 15.178 \%$ and $7.936 \%$ of the total variances respectively, which made total percentage variance explained for market orientation $=66.95 \%$. According to Hair et al., (2010), factors which is having eigenvalues greater than one (1) is significant. In order to support the validity as suggested by Narver and Slater (1990) one-factor solution EFA also performed. Results indicated that eigenvalues $=6.8$ with $43.84 \%$ of variance explained whereby in the same range of results of Narver and Slater (1990) that is eigenvalues $=7.1$ with $44.8 \%$ of the variance explained. Although the result is slightly lower, nevertheless the difference between the two is very small that is less than 1 .

For reliability analysis, the Cronbach's Alpha for all the variables scales were in the range of 0.855 to 0.890 , well above the minimum acceptable reliability of 0.6 as suggested by Sekaran and Bougie (2010) and Hair et al.,(2006). The independent variable (Market Orientation) scales and dependent variables (Performance of Takaful Business in Malaysia) scales with Cronbach's alpha of .890 and 0.855 respectively as per Table 4.3 below.

Table 3. Reliability analysis for all variables

\begin{tabular}{lcc}
\multicolumn{1}{c}{ Variable } & N of Item & Cronbach Alpha \\
\hline Performance & 7 & 0.855 \\
Market Orientation & 15 & 0.890 \\
\hline
\end{tabular}

As regard to correlation analysis, the three dimensions of independent variables, customer orientation, competitor orientation and inter-functional coordination carried a mean score rating which was $\mathrm{M}=3.59$, $\mathrm{SD}=0.88 ; \mathrm{M}=3.7, \mathrm{SD}=0.8$ and $\mathrm{M}=3.47, \mathrm{SD}=0.94$ respectively. For dependent variable, the performance of Takaful Business in Malaysia, the mean score value was considered high which was $\mathrm{M}=3.95$ and $\mathrm{SD}=0.71$ respectively. Based on the above result, it indicates that the responses range of this study was satisfactorily over the scale. There was a strong positive correlation between Customer Orientation and Performance $(\mathrm{r}=0.564$, $\mathrm{n}=111, \mathrm{p}<0.01$ ) with high levels of customer orientation associated with high level of performance. There was a strong positive correlation between Competitor Orientation and Performance $(r=0.502, n=111, p<0.01)$ with high levels of competitor orientation associated with high level of performance. There was as strong positive correlation between Inter-functional Coordination and Performance $(r=0.569, n=111, p<0.01)$ with high levels of interfunctional coordination associated with high level of performance. In summary, all the variables are categorized within the large (Pallant, 2007) scale of correlation $(0.50-1.0)$ and therefore, there was a strong positive correlation between the variables.

Regression analysis on Market Orientation and Performance was also performed. From the results, the $\mathrm{R}^{2}$ is 0.389 (significant $=\mathrm{p}$-value $<0.01$ ) which means that $38.9 \%$ of the variation in the performance can be explained by customer orientation, competitor orientation and inter-functional coordination. The results also shows that only customer orientation (beta $=0.307, \mathrm{p}=0.005<0.05$ ) and inter-functional coordination (beta $=0.291$, $\mathrm{p}=0.017<0.05$ ) has a significant and positive effect on performance. Even though competitor orientation is not significant (beta $=0.169, \mathrm{p}=0.379>0.05$ ) but it is positively related to performance. Thus, all hypotheses H1a, $\mathrm{H} 1 \mathrm{~b}$ and $\mathrm{H} 1 \mathrm{c}$ are supported. Based on the Beta values, Inter-functional coordination has the highest impact on performance followed by customer orientation. This results also shows that there is no autocorrelation exist ( $\mathrm{D}-\mathrm{W}=1.729$, within the range of 0 to 4 ). F-value $=22.703$ which is higher than F-statistic (mean square/ total sum of square $=>3.871 / 29.857$ ) and $\mathrm{p}=0.000<001$ shows the homoscedasticity or homogeneity of variance of the data.

\section{Conclusion and Implications}

The study examined the relationship between Market Orientation and Takaful performance. Based on the 111 samples of respondent, this survey affirmed that Takaful business in Malaysia performs moderately and moving towards a better performance level. The results of this study also revealed that market orientation constructs are 
positively related with performance of the Takaful business in Malaysia. Being equally important and significantly influence performance, customer orientation and inter-functional coordination dominated the model with the beta values of 0.307 and 0.291 respectively. These results indicate the importance of having a good customer focus and a good internal communication within the organization in order to achieve the organizational goals. The $\mathrm{R}^{2}$ value of 0.389 suggests that market orientation explains $38.9 \%$ of the performance parameters. Therefore, this study has proven that market orientation is beneficial to the performance achievement in Malaysian Takaful business. Empirically, this study highlights that market orientation does significantly influence performance of Takaful business in Malaysia basically by focusing on customer and inter-functional coordination. Concentration on the customer welfare as well as the employees will definitely result in a better performance. Satisfied customers will always support the organization by loyalty and repeat purchase. Also, good inter-departmental communication within the organization will improve the services provided as well as collects information on the organization's activities effectively and successfully accommodate the requirement of superior performance of the organization. In conclusion, findings of this study will be beneficial to managers and decision making levels of Takaful Operators to augment and upgrade their marketing strategy by gaining superior performance and increase the penetration of Takaful market in Malaysia.

\section{Acknowledgements}

The author would like to convey special thanks to our sponsor, University of Sultan Zainal Abidin, Kuala Terengganu for providing the financial grant to this research.

\section{References}

Alchian, A., \& Demsetz, H. (1972). Production, information costs and economic organization. The American Economic Review, 777-795. http://dx.doi.org/10.2307/1815199

Dawes, J. (2000). Market orientation and company profitability: Further evidence incorporating longitudinal data. Australian Journal of Management, 25(2), 173-199. http://dx.doi.org/10.1177/031289620002500204

Day, G. S. (1990). Market driven strategy; Processes for creating value. New York: Free Press.

Deshpande, R., Farley, J. U., \& Webster, F. E. (1993, January). Corporate culture, customer orientation and innovativeness in Japanese firms: A quadrad analysis. Journal of Marketing, 57, 23-37. http://dx.doi.org/10.2307/1252055

Drucker, F. (1998). The discipline of innovation. Harvard Business Review. http://dx.doi.org/10.1002/lt1.40619980906

Ellis, P. D. (2005). Market orientation and marketing practice in a developing economy. European Journal of Marketing, 39(5-6), 629-645. http://dx.doi.org/10.1108/03090560510590746

Ellis, P. D. (2006). Market orientation and performance: A meta-analysis and cross-national comparisons. Journal of Management Studies, 43(5), 1089-1107. http://dx.doi.org/10.1111/j.1467-6486.2006.00630.x

Hair, J. J. F., Black, W. C., Babin, B. J., \& Anderson, R. E. (2010). Multivariate Data Analysis: A Global Perspective. London: Pearson.

Han, J. K., Kim, N., \& Srivasta, R. K. (1998). Market orientation and organizational performance: Is innovation the missing link? Journal of Marketing, 62, 30-45. http://dx.doi.org/10.2307/1252285

Homburg, C., Hoyer, W. D., \& Fassnacht, M. (2002, October). Service orientation of a retailer's business strategy: Dimensions, antecedents, and performance outcomes. Journal of Marketing, 66, 86-101. http://dx.doi.org/10.1509/jmkg.66.4.86.18511

Im, S., \& Workman, J. J. P. (2004). Market orientation, creativity, and new product performance in high technology firms. The Journal of http://dx.doi.org/10.1509/jmkg.68.2.114.27788

Kaiser, H. F., \& Rice, J. (1974). Little Jiffy, Mark IV. Educational and Psychological Measurement, 34, $111-117$. http://dx.doi.org/10.1177/001316447403400115

Kohli, A. K., \& Jaworski, B. J. (1990). Market orientation: The construct, research propositions and managerial implications. Journal of Marketing, 54(2), 1-18. http://dx.doi.org/10.2307/1251866

Kumar, K., Subramaniam, R., \& Yauger, C. (1998). Examining market orientation-performance relationship: A context-specific study. Journal of $201-233$. http://dx.doi.org/10.1177/014920639802400204 
Mokhtar, S. S. M., Yusoff, R. Z., \& Arshad, R. (2009). Market orientation critical success factors of Malaysian manufacturers and its impact on financial performance. International Journal of Marketing Studies, 1(1), 77-84.

Narver, C., \& Slater, F. (1990). The effect of market orientation on business profitability. Journal of Marketing, 54(4), 20-35. http://dx.doi.org/10.2307/1251757

Narver, C., Slater, F., \& Tietje, B. (1998). Creating a market orientation. Journal of Market-Focused Management, 2(3), 241-255. http://dx.doi.org/10.1023/A:1009703717144

Ngai, J. C. H., \& Ellis, P. (1998). Market orientation and business performance: Some evidence from Hong Kong. International Marketing Review, 15(2), 119-139. http://dx.doi.org/10.1108/02651339810212502

Pelham, A. M., \& Wilson, D. T. (1996). A longitudinal study of the impact of market structure, firm structure, strategy and market orientation culture on dimensions of small-firm performance. Journal of the Academy of Marketing Science, 24(1), 27-43. http://dx.doi.org/10.1177/009207039602400103

Richard, P., Devinney, T., Yip, G., \& Johnson, G. (2009). Measurement organizational performance: Towards methodological best practice. Journal of Management, 35, 718-804. http://dx.doi.org/10.1177/0149206308330560

Ruekert, R. W. (1992). Developing a market orientation: an organizational strategy perspective. International Journal of Research in Marketing, 9, 225-245. http://dx.doi.org/10.1016/0167-8116(92)90019-H

Ruibyte, E., Haahti, A., \& Pesämaa, O. (2007). Influences of market orientation and perceived trust on innovativeness and performance in tourism networks.

Sekaran, U., \& Bougie, R. (2010). Research methods for business. John Wiley \& Sons.

Slater, F., \& Narver, C. (1994). Market orientation, customer value, and superior performance. Business Horizon, 22-28. http://dx.doi.org/10.1016/0007-6813(94)90029-9

Venkatraman, N., \& Ramanujam, V. (1986). On the measurement of business performance in strategy research: A comparisons of approaches. The Academy of Management Review, 11(4), 801-814. http://www.jstor.org/stable/258398

Zaltman, G., Duncan, R., \& Holbek, J. (1973). Organizational change; Diffusion of innovations. New York: Wiley. 